\title{
O FENÔMENO DOS MPAS BRASILEIROS: HIBRIDISMO, DIVERSIDADE E TENSÕES
}

RESUMO

Na década de 1990, os programas de MBA - M aster in Business Administration - ganharam sólida reputação e expandiram-se para além das fronteiras norte-americanas. No Brasil, o movimento ganhou força com 0 crescimento vigoroso do ensino profissionalizante de gestão. Este artigo tem como objetivo apresentar e analisar, sob uma perspectiva crítica, o fenômeno dos M estrados Profissionais em Administração (M PAs) brasileiros. Para traçar um retrato do fenômeno, realizamos pesquisa bibliográfica e documental, e entrevistas com coordenadores e pessoas-chave dos principais programas locais. Apesar de eventualmente classificados como MBAs, os MPAs apresentam características que os diferenciam do modelo norteamericano. Ao buscar responder ao contexto socioeconômico e às restrições regionais, cada um deles seguiu rotas próprias, o que gerou um quadro marcado pela diversidade. Acreditamos que o fenômeno que este artigo descreve e analisa possa contribuir para o debate em curso sobre o ensino de Administração.

\section{Thomaz Wood Jr.}

FGV-EAESP

\section{Ana Paula Paes de Paula \\ FGV-EAESP/ FAPESP}

\begin{abstract}
In the 1990s, M BA - Master in Business Administration - programs won a solid reputation and expanded beyond U.S. frontiers. In Brazil, this movement got momentum with the impressive growth of executive education in management. This paper aims to present and analyze the phenomenon of Professional M asters in Business Administration (M PA, in Portuguese). To describe this phenomenon, we conducted bibliographic and documental research and made interviews with coordinators and key-persons from local programs. Albeit being eventually classified as MBAs, the MPAs' characteristics make them remarkably different from the $\mathrm{N}$ orth American blueprint. By attempting to align with its regional social and economic context, each program followed its own route, generating a landscape char acterized by diversity. We believe that the phenomenon this article describes and analyzes can make a contribution to the current debate over business education.
\end{abstract}

PALAVRAS-CHAVE MBA, MPA, ensino de Administração, educação executiva, indústria do management.

KEY WORDS MBA, MPA, business education, executive education, management industry. 


\section{INTRODUÇÃO}

Na década de 1990, os programas de MBA - Master in Business Administration - ganharam sólida reputação e expandiram-se para além das fronteiras norte-americanas. No Brasil, o movimento ganhou força com 0 crescimento vigoroso do ensino profissionalizante de gestão, gerando, desde o primeiro momento, experimentos interessantes e ambíguos, marcados tanto pela dimensão comercial quanto pela dimensão pedagógica. 0 observador menos atento poderia localizar no fenômeno apenas mais um caso de importação ou transplante de idéias vindas de um país desenvolvido. Porém, por trás da fachada, emergiram padrões e modelos múltiplos.

A educação executiva, e os M BAs em particular, têm sido objeto de intensa atenção de pesquisadores (ver Gioia e Corley, 2002; Mintzberg e Gosling, 2002; M intzberg e Lampel, 2001; Warde, 2000; Fox e Grey, 2000; Antonacopoulou, 1999; Dehler, Welsh e Lewis, 1999; Gold, Holman e Thorpe, 1999; Reynolds, 1997; Boje, 1996; Grey e French, 1996; Grey, Knights e Willmott, 1996; Robert, 1996; Willmott, 1994; Warner, 1990). No Brasil, entretanto, são raros os trabalhos publicados que tratam do ensino no nível de pós-graduação voltado para executivos. U ma notável exceção é o trabalho de Ruas (2003), que trata da questão da identidade dos programas de M PA. 0 autor reconhece a importância dos MPAs como supridores de demandas dos executivos e empresas e propõe um aprofundamento do debate acerca do desenvolvimento de competências.

Neste artigo, apresentamos e analisamos o fenômeno dos Mestrados Profissionais em Administração MPAs -, um grupo reduzido de programas conduzidos por instituições de renome. N osso objetivo é traçar um perfil deste segmento do ensino da Administração no Brasil e contribuir para sua compreensão. Para isso empreendemos, entre março e agosto de 2002, uma pesquisa de campo que envolveu a análise de documentos e entrevistas em profundidade com coordenadores e pessoas-chave de seis programas de M PA.

Este artigo está estruturado da seguinte forma: a seção seguinte apresenta a polêmica internacional que envolve os cursos de MBA. Tal polêmica, polarizada entre dois discursos antagônicos, constitui o pano de fundo para a análise de nosso objeto de investigação. Em seguida, sumariamos a evolução recente do ensino de Administração no Brasil, preparando o terreno para apresentarmos os resultados e traçarmos o perfil dos M PAs brasileiros. $\mathrm{N}$ a seção seguinte apresentamos a polêmica em torno da qualificação dos MPAs como MBAs e procuramos identificar os fatores que moldaram os M PAs. $\mathrm{Na}$ última seção concluímos o texto com reflexões adicionais sobre os MPAs e apresentamos sugestões para futuras pesquisas.

\section{O DISCURSO DA REDENCC̃OO E O DISCURSO DA CRÍTICA}

\section{Origens das escolas de negócios}

Os primeiros cursos de Administração tiveram início em 1881, com a criação da Wharton School (Castro, 1981). Os MBAs foram introduzidos nas escolas de negócios norte-americanas em 1908 e sua popularização catalisou a expansão dessas escolas. $\mathrm{Na}$ década de 1950, os Estados U nidos já formavam cerca de 50 mil bacharéis, 4 mil mestres e 100 doutores em Administração por ano.

Nos anos 1960 e 1970, ocorreu uma expansão dos programas de $\mathrm{PhD}$, além de uma consolidação do Master in Business Administration - MBA (Ehrensal, 1999). Na mesma época, as escolas de Administração transformaram-se em produto de exportação e conheceram sua primeira "era dourada".

$\mathrm{Na}$ Europa, a disseminação dos M BAs derivou do Plano $M$ arshall e da expansão das multinacionais norte-americanas (Warde, 2000). No início dos anos 1990, o modelo norte-americano já havia se espal hado por todo 0 continente: as universidades de C ambridge e Oxford, símbolos do ensino clássico, abriram escolas de negócios, e várias universidades francesas criaram MBAs.

Paralelamente, periódicos como BusinessWeek e Financial Times criaram seus rankings, definindo critérios de julgamento que passaram a estimular a competição entre escolas. Esses rankings tiveram profundo impacto na gestão das escolas: tal como empresas que perseguem a liderança do mercado, muitas delas contrataram reitores com experiência em melhorar resultados, implantaram programas de mudança e passaram a monitorar cuidadosamente cada tópico da lista. Segundo Gioia e Corley (2002), os rankings estão transformando a "substância" das escolas de negócios em "imagem", um fenômeno que deve ser cuidadosamente entendido e merece um engajamento pró-ativo dos acadêmicos.

0 debate em torno dos MBAs não é novo e evoluiu progressivamente, acirrando-se nos anos 1990. De acordo com Mintzberg e Lampel (2001), no final da 
década de 1950 os programas passaram por um sério escrutínio a fim de reforçar seu lado teórico e analítico. $\mathrm{N}$ a década de 1980, 0 assunto veio novamente à tona (ver Warde, 2000): apesar das reformulações, vários críticos afirmavam que a formação oferecida pel os M BAs incentivava a reflexão voltada para o curto prazo, além de privilegiar as áreas de marketing e finanças em detrimento das áreas de produção e de inovações tecnológicas.

Algumas dessas críticas motivaram reformas nas escolas de negócios que parecem ter fracassado novamente em atender às expectativas, pois, durante a década de 1990, prosseguiu a discussão sobre a crise do ensino de gestão e dos MBAs. Uma prova disso é o debate que a Harvard Business Review publicou sobre o tema. Seguindo o padrão da revista, Linder e Smith (1992) elaboraram um caso que ganhou o título de The complex case of management education. Nesse texto, os autores retratam as queixas de um CEO fictício, Jim Martin, sobre os resultados frustrantes dos profissionais com MBA por ele contratados. $\mathrm{Na}$ edição seguinte, o caso foi comentado por oito especial istas gerentes, docentes e pesquisadores - gerando o debate intitulado M BA: is the traditional model dommed?. 0 debate colocava em questão a eficácia dos programas e dos métodos de ensino empregados nos MBAs.

Entre os especialistas figurava Henry Mintzberg, que afirmou que os gerentes não poderiam continuar sendo treinados por meio de estudos de casos fragmentados e teorias desconectadas. Poucos anos antes, Warner (1990) havia constatado problemas semel hantes: segundo ele, as escolas de negócios fal ham em atender as necessidades das empresas porque se valem de um discurso generalista, mas acabam focalizando especialidades funcionais, sem atentar ad equadamente para a interdependência dos aspectos que dizem respeito à gestão.

\section{0 discurso da redenção na mídia de negócios}

Examinando a trajetória desse debate, notamos que há uma polarização entre duas posições: o "discurso da redenção" e o "discurso da crítica", situação que alguns observadores poderiam qualificar como maniqueísta, pois sem dúvida as posições são extremas.

0 discurso da redenção pode ser observado na mídia de negócios nos Estados Unidos, na Europa e também no Brasil: os programas de MBA são comumente retratados como um caminho seguro para o sucesso na carreira (ver Jacomino, 1999, 2000, 2001; Gomes, 1996; Sganzerla, 1995), além de uma porta para um novo mundo, globalizado e cheio de oportunidades para os mais qualificados. Na mídia brasileira, o discurso da redenção se baseou principalmente nas características dos M BAs norte-americanos e europeus. Em dois artigos típicos publicados na revista Exame, os jornalistas destacam:

“Há três anos, o engenheiro químico paulista Danny Siekierski, então com 28 anos, lançou-se no que, à primeira vista, poderia parecer uma aventura: abandonou um promissor posto de chefe de produção na subsidiária brasileira da Procter \& Gamble para voltar aos bancos escolares... seu objetivo era obter no exterior um diploma de $M$ aster of Business Administration (MBA), uma espécie de passaporte para o futuro que povoa os sonhos de jovens executivos como el e... Ao receber seu canudo de MBA em maio do ano passado, tinha nas mãos quatro ofertas de emprego, uma delas lá fora mesmo". (Sganzerla, 1995, p.108-109).

"Poucos sonhos habitam mais o imaginário do executivo hoje do que um diploma de MBA. 0 Master in Business Administration, mestrado em Administração de Empresas, é a promessa para carreiras em ascensão, salários milionários e, sonho dos sonhos, para a cadeira de presidente de uma companhia de respeito".(Gomes, 1996, p.112).

Na revista VocêS.A. podemos encontrar vários exemplos da imagem projetada dos MBAs. As peças publicitárias desses cursos freqüentemente apelam para 0 impacto na carreira e na vida profissional (Você S.A., 2001; 2000):

- "D estaque-se no mundo dos negócios: executivos para o século XXI" - FAAP

- "FGV-M anagement: sempre perto de quem quer ir mais longe" - FGV

- "U m futuro de resultados" - PUC-SP

- "A porta certa para o novo mundo profissional" - IN PG

- "O globalizado mundo dos negócios em suas mãos" FEA-USP

Nas revistas estrangeiras, a abordagem é similar. Aqui temos al guns exemplos coletados da revista britânica The Economist (2002a; 2002b), que tem uma grande seção publicitária dedicada à educação em gestão:

- "You will be transformed" - Chicago GSB

- "You have the potential ... Lift your career beyond 
expectations" - INSEAD

- "How far will you go?" - ISMA Centre / The University of Reading

- "Developing tomorrow's leaders" - Cranfield University

- "The world in your class" - Rotterdam School of Management

- "Global approach: see with your eyes what very few have the privilege of seeing" - IESE

Embora, aos ol hos de al guns pesquisadores, tal discurso possa parecer exagerado ou estereotipado, devemos observar que ele retrata o "discurso oficial" sobre os MBAs, e reflete tanto os anseios e expectativas dos profissionais que procuram tais cursos como a retórica empregada pelas escolas que os promovem.

\section{0 discurso da crítica: a análise da eficácia}

0 discurso da crítica, que se consolidou nos anos 1990, é herdeiro de debates ocorridos em décadas anteriores. De forma geral, esse discurso pode ser dividido em dois grandes grupos: 1) a corrente representada por Henry Mintzberg e colaboradores, que coloca em cheque a eficácia desses programas para a formação de administradores, que veremos nesta subseção; e 2) a crítica ao conteúdo e à pedagogia dos programas, expressa pelos pesquisadores envolvidos com a corrente de Critical Management Studies (CMS), que veremos na próxima subseção.

Henry Mintzberg vem dirigindo suas preocupações para o impacto dos profissionais com título de MBA nas empresas. Esse professor e pesquisador advoga que as escolas de gestão insistem em promover uma abordagem desastrosa: muitos profissionais com M BA irão flanar de empresa em empresa sem nunca entender realmente como as coisas funcionam, portando-se como se estivessem em um ambiente escolar. Mintzberg argumenta que os programas não capacitam para gerir, mas fazem crer que capacitam. Ensinam a retórica gerencial e fazem os estudantes acreditar que podem controlar situações e solucionar problemas complexos de um dia para o outro.

Para ilustrar o argumento, uma pesquisa realizada por Mintzberg e Lampel (2001) comprova o fracasso de alguns egressos de MBAs que assumiram posições gerenciais em destacadas companhias norte-americanas. Examinando a lista Ewing (1990), publicada no livro Inside the Harvard Business School, que aponta os 19 mais famosos graduados em $\mathrm{H}$ arvard, os pesquisadores constataram que 10 del es fracassaram: ou leva- ram a companhia à falência, ou foram demitidos em função de desempenho insatisfatório. Apesar disso, em 1998, 42\% das 100 maiores companhias dos Estados Unidos eram administradas por MBAs, contra cerca de 33\% em 1991.

0 próprio M inzberg desenvolveu um modelo alternativo aos programas de $M B A$, que recebeu o nome de Programa Internacional de Desenvolvimento de Executivos (Mintzberg e Gosling, 2002). Os pilares do modelo são os seguintes: a utilização da experiência profissional dos estudantes; a vivência internacional; e o uso de uma pedagogia própria, que inclui uma disposição física especial para as salas de aula, e uma grande interação entre os estudantes.

\section{0 discurso da crítica no âmbito dos Critical Management Studies}

0 acirramento da crítica aos M BAs na década de 1990 também pode ser relacionado a ascensão da corrente dos Critical Management Studies - CM S (ver Alvesson e W illmott, 1992; 1993 e Alvesson e Deetz, 1996). Os autores filiados aos CMS apontam os seguintes problemas no ensino de gestão (Fox e Grey, 2000; Antonacopoulou, 1999; Dehler, Welsh e Lewis, 1999; Gold, Holman e Thorpe, 1999; Reynolds, 1997; Boje, 1996; Grey e French, 1996; Grey, Knights e Willmott, 1996; Robert, 1996; Willmott, 1994):

- as concepções e visões tradicionais do ensino de gestão são cada vez menos aceitáveis pois costumam reduzir excessivamente a complexidade dos fenômenos examinados;

- a tendência à instrumentalidade do conhecimento é cada vez mais acentuada, com o uso de receitas prontas, o que leva os estudantes a aprenderem a reprodução de técnicas, em vez da realização de diagnósticos;

- os conteúdos e métodos do ensino de gestão estão se tornando cada vez menos efetivos;

- os estudantes estão sendo considerados meros espectadores do processo de ensino, e quase não há incentivo à autonomia e ao autodidatismo; e

- o ensino de gestão está sofrendo forte processo de "mercadorização".

Tais autores também discutem como poderia ser realizada uma renovação do ensino de Administração, abordando questões como conteúdo, métodos pedagógicos, ligação entre teoria e prática e, principalmente, o desenvolvimento da visão crítica e do raciocínio analítico entre os estudantes. 
No que se refere aos MBAs, a crítica à "mercadorização" ganha destaque. Tal questão foi inicialmente abordada por Parker e Jary (1995). Inspirados por Ritzer (1993), esses autores apontam uma progressiva "mcdonaldização" das universidades britânicas, com a emergência de uma elite especial izada voltada para a padronização da educação superior.

Sturdy e Gabriel (2000) também abordam o MBA como mercadoria de uma forma bastante direta. Analisando o caso da Malásia, os autores concluem que a educação na área de gestão está se tornando um bem comercial, e as universidades ocidentais cada vez mais competem nos mercados emergentes por oportunidades lucrativas e por estudantes ("consumidores"). Nesse contexto, o MBA seria como um produto padronizado, porém com alto valor simbólico, já que implica status, prestígio e poder.

Ainda segundo os autores, a partir da década de 1950 o conhecimento sofreu um processo de padronização: surgiram livros, vídeos e pacotes educacionais que em seguida passaram a ser exportados. Q uando se compara a área de Administração com outras áreas do conhecimento (como a Filosofia ou a História), nota-se que a primeira adquiriu características de bem de consumo muito rapidamente. Isso parece estar associado à tendência à instrumentalidade dos estudantes - que dão prioridade à realização prática e resultados - aos interesses dos professores e ao próprio mercado de educação. N esse contexto, os M BAs emergem como pacotes padronizados de educação gerencial, com preços rel ativamente altos, que oferecem ao consumidor a promessa de mel horar suas perspectivas de carreira e de renda.

No Brasil, Nicolini (2003) segue uma linha crítica similar, ao qual ificar os cursos de Administração como fábricas. 0 autor refere-se especificamente aos cursos de graduação, porém parece aceitável estender seus argumentos aos cursos de pós-graduação voltados para executivos.

A partir do ano 2000, os escândal os financeiros ocorridos nos Estados Unidos, que envolveram egressos dos cursos de M BA, incorporaram a dimensão ética ao debate. Em artigo recente, Schneider (2002) comenta a pesquisa do Aspen Institute com 1978 estudantes de MBA formados em 2001 em 13 escolas de Administração de primeira linha nos Estados Unidos. Segundo a autora, os representantes das instituições abordadas afirmam que estão tentando ensinar que é preciso levar em consideração o meio ambiente e os interesses de longo prazo. No entanto, apenas $7 \%$ dos homens e $14 \%$ das mulheres entrevistados afirmaram que levam em consideração os padrões éticos de uma companhia quando avaliam uma oferta de emprego. Os resultados apontam que as atitudes e valores das pessoas que terminam o curso de MBA mudam, mas não necessariamente para melhor (ver Adler, 2002; Gioia, 2002).

Visto em seu conjunto, o discurso da crítica aponta para uma reformulação profunda dos programas de MBA, em seus aspectos pedagógicos, de conteúdo e ético-comportamentais. Por outro lado, o volume e 0 teor da crítica representam também o reconhecimento da popularidade e importância de tais cursos para a formação dos executivos e para a gestão das empresas.

\section{PESQUISA DE CAMPO}

\section{Abordagem de investigação}

Para traçar um retrato dos M PAs brasil eiros, empreendemos, entre março e agosto de 2002, uma pesquisa de campo que envolveu a anál ise de documentos e entrevistas em profundidade com 10 coordenadores e pessoas-chave de seis programas de MPA, realizados por cinco instituições em cinco estados.

As entrevistas foram realizadas com base em um roteiro de 32 questões divididas em 11 partes, compreendendo os seguintes tópicos: histórico do programa, caracterização do público, informações sobre custos, percepção sobre a demanda dos estudantes, estrutura do programa, pedagogia empregada, perfil dos professores, relações internacionais, percepção de impacto sobre os estudantes e as empresas, e comentários gerais. 0 roteiro combinava questões abertas e fechadas. Além do roteiro, procurou-se também estimular os entrevistados a expressar percepções e opiniões sobre 0 ensino de Administração em geral e os programas de M PA especificamente. Cada entrevista teve a duração média de 90 minutos. Durante as entrevistas, a pesquisadora tomou notas e fez uso de um gravador, com a autorização dos entrevistados. As gravações foram transcritas sel etivamente pela pesquisadora.

A subseção seguinte apresenta uma introdução histórica sobre a evolução do ensino da Administração no Brasil. As subseções posteriores trazem os resultados da pesquisa de campo.

\section{Origens e situação atual}

No Brasil, como em outros países emergentes, o desenvolvimento da Administração como campo de ensino e pesquisa pode ser relacionado ao processo de industrialização. 0 ponto de inflexão ocorreu na dé- 
cada de 1940, quando a economia deixou de ser essencial mente agrária e iniciou-se a expansão dos setores industriais e de serviços ( $M$ artins, 1989). 0 desenvolvimento do ensino de Administração no Brasil se articulou em torno da criação da Faculdade de Economia e Administração - FEA, da Universidade de São Paulo, e das Escolas de Administração da Fundação Getulio Vargas - FGV, na segunda metade da década de 1940.

0 primeiro curso especificamente voltado para a Administração de Empresas foi criado em 1954, na Escola de Administração de Empresas de São Paulo - EAESP, da FGV. A gênese de outras escolas também ocorreu entre as décadas de 1940 e 1950. Em 1951, nasceu a Faculdade de Ciências Econômicas, da Universidade Federal do Rio Grande do Sul - UFRGS, cuja Escola de Administração se tornaria uma unidade autônoma em 1996. Em 1954, foi criado o Instituto de Administração e Gerência - IAG, da Pontifícia Universidade Católica do Rio de Janeiro. Em 1959, surgiu a Escola de Administração da Universidade F ederal da Bahia EA-UFBA. Essas escolas implantaram seus cursos de graduação em Administração a partir da década de 1960, momento em que começou também a se desenvolver o ensino de pós-graduação.

Durante a década de 1960, a FGV criou cursos de pós-graduação nas áreas de Administração Pública e Administração de Empresas, iniciando a oferta regular de cursos de mestrado, o que habilitou a instituição a formar professores para outras escolas. Nas décadas seguintes, outras escolas criaram seus cursos, de modo que nos anos 1990 o campo da pós-graduação em Administração havia sofrido uma considerável expansão e diversificação.

No ano 2000, havia no Brasil, de acordo com o Ministério da Educação, 969 cursos de graduação, 28 programas de mestrado e 10 programas de doutorado. Em agosto de 2002, o número de cursos de graduação atingiu a espantosa soma de 2687. 0 número de programas de pós-graduação, por sua vez, cresceu a taxas mais modestas.

No âmbito do ensino de pós-graduação voltado para executivos, entre a segunda metade da década de 1990 e o início de 2000, três tipos de programas se consolidaram:

- primeiro, cerca de 10 programas batizados de MPA (Mestrado Profissional em Administração) e realizados por grandes universidades públicas e escolas autônomas tradicionais. Tais programas representam de certa forma uma elite do ensino de Administração para executivos no país;
- segundo, um número expressivo de MBAs Executivos, programas de pós-graduação lato sensu com carga horária mínima de 360 horas, alguma similaridade com os norte-americanos, porém apresentando múltiplas especializações;

- terceiro, um número expressivo, porém também de difícil estimativa, de programas de educação executiva - inclusive programas fechados para empresas - , com carga horária variada, e que utilizam com muita liberdade o rótulo MBA.

\section{Perfil dos MPAs}

Os M PAs foram criados a partir de sua regularização, em 1998. A única exceção é o programa da F GV-EAESP, criado em 1993 e credenciado posteriormente. O Quadro 1 traz informações sobre os seis programas reconhecidos pelo governo brasileiro em 2001, que foram analisados em nossa pesquisa de campo. Cabe observar que, em 2002, mais quatro programas passaram a integrar a lista. Esses não foram considerados na pesquisa.

Os M PAs apresentam diferenças substantivas em reIação aos M BAs norte-americanos e europeus. A partir dos dados e informações do Quadro 1, as seguintes informações devem ser enfatizadas.

Quanto à origem dos alunos, deve-se primeiro destacar o fato de que os MPAs são cursos de tempo parcial, e quase todos os estudantes os realizam à noite e/ ou nas sextas-feiras e sábados, sem se afastarem de seus empregos. A maioria desses estudantes vem de empresas médias e grandes. Constituem casos extremos a FGV-EAESP, com $90 \%$ dos alunos vindo de empresas médias e grandes, e a EA-UFRGS, com $45 \%$ dos alunos vindo de pequenas empresas, onde atuam como empreendedores ou consultores.

Quanto ao perfil dos alunos, observa-se uma média de idade superior àquela apresentada por MBAs internacionais: os brasileiros, à exceção dos al unos da FGV-EAESP, parecem procurar os M PAs mais tarde que seus colegas estrangeiros. Eles também se situam em postos relativamente mais al tos na hierarquia da empresa. 0 percentual de mulheres nos programas, embora baixo se comparado a referências externas, deve ser visto em relação ao contexto local, em que a presença feminina em cargos executivos é baixa, porém crescente.

Quanto às taxas escolares, verifica-se que os M PAs constituem uma al ternativa de baixo custo em relação aos MBAs no exterior. Além disso, deve-se destacar o fato de constituírem cursos de tempo parcial, com freqüência pagos ( total ou parcialmente) pelas empresas 
nas quais os profissionais atuam.

Quanto a classes e métodos, chama a aten ção o tamanho reduzido das turmas. Isso é justificado em parte por imperativos pedagógicos, em parte pelo nível de exigência de dedicação dos cursos, o que limita 0 número de interessados.

Quadro 1 - Características gerais dos cursos pesquisados.

\begin{tabular}{|c|c|c|c|c|c|c|c|}
\hline \multicolumn{2}{|c|}{ PROGRAMA } & IBMEC-RJ & FGV-EAESP & FGV-EBAPE & PUC-RJ & EA-UFBA & EA-UFRGS \\
\hline \multicolumn{2}{|r|}{ Criação } & 2000 & 1993 & 1999 & 2001 & 1999 & 1998 \\
\hline \multirow{3}{*}{$\begin{array}{l}\text { Origem } \\
\text { dos alunos }\end{array}$} & $\begin{array}{l}\text { Grandes } \\
\text { empresas }\end{array}$ & $30 \%$ & $60 \%$ & $40 \%$ & $40 \%$ & $60 \%$ & $30 \%$ \\
\hline & Médias empresas & $40 \%$ & $30 \%$ & $30 \%$ & $30 \%$ & $10 \%$ & $25 \%$ \\
\hline & $\begin{array}{l}\text { Pequenas empre- } \\
\text { sas e outros }\end{array}$ & $30 \%$ & $10 \%$ & $30 \%$ & $30 \%$ & $30 \%$ & $45 \%$ \\
\hline \multirow[b]{2}{*}{$\begin{array}{l}\text { Taxas } \\
\text { escolares }\end{array}$} & Total (US\$) & 10.000 & 16.000 & 6.500 & 10.000 & 7.000 & 11.000 \\
\hline & $\begin{array}{l}\text { Quem paga } \\
\text { (empresa, estu- } \\
\text { dante, bolsa) }\end{array}$ & $\begin{array}{l}38 \% \text { empresa } \\
40 \% \text { empresa/ } \\
\text { estudante } \\
20 \% \text { estudante } \\
2 \% \text { bolsa }\end{array}$ & $\begin{array}{l}20 \% \text { empresa } \\
40 \% \text { empresal } \\
\text { estudante } \\
40 \% \text { estudante }\end{array}$ & $\begin{array}{l}50 \% \text { empresa } \\
30 \% \text { empresa/ } \\
\text { estudante } \\
20 \% \text { estudante }\end{array}$ & $\begin{array}{l}60 \% \text { empresa } \\
20 \% \text { empresa/ } \\
\text { estudante } \\
20 \% \text { estudante }\end{array}$ & $\begin{array}{l}10 \% \text { empresa } \\
70 \% \text { empresa/ } \\
\text { estudante } \\
10 \% \text { estudante } \\
10 \% \text { bolsa }\end{array}$ & $\begin{array}{l}5 \% \text { empresa } \\
15 \% \text { empresa/ } \\
\text { estudante } \\
80 \% \text { estudante }\end{array}$ \\
\hline \multirow{5}{*}{$\begin{array}{l}\text { Classes } \\
\text { e métodos }\end{array}$} & Alunos por turma & 30 & 50 & 25 a 30 & 30 & 35 a 40 & 25 a 30 \\
\hline & $\begin{array}{l}\text { Estrutura geral } \\
\text { do curso }\end{array}$ & $\begin{array}{c}6 \text { disciplinas } \\
\text { obrigatórias e } \\
3 \text { eletivas }\end{array}$ & $\begin{array}{c}22 \text { disciplinas } \\
\text { obrigatórias e } \\
6 \text { eletivas }\end{array}$ & $\begin{array}{c}10 \text { disciplinas } \\
\text { obrigatórias e } \\
2 \text { eletivas }\end{array}$ & $\begin{array}{c}18 \text { disciplinas } \\
\text { obrigatórias e } \\
3 \text { eletivas }\end{array}$ & $\begin{array}{c}10 \text { disciplinas } \\
\text { obrigatórias e } \\
2 \text { eletivas }\end{array}$ & $\begin{array}{l}15 \text { disciplinas } \\
\text { obrigatórias e } \\
\text { seminário } \\
\text { internacional } \\
\text { obrigatório }\end{array}$ \\
\hline & Aulas expositivas & $45 \%$ & $60 \%$ & $70 \%$ & $50 \%$ & $60 \%$ & $65 \%$ \\
\hline & Estudos de caso & $35 \%$ & $20 \%$ & $20 \%$ & $20 \%$ & $20 \%$ & $20 \%$ \\
\hline & $\begin{array}{l}\text { Dinâmicas basea- } \\
\text { das em grupo }\end{array}$ & $20 \%$ & $20 \%$ & $10 \%$ & $30 \%$ & $20 \%$ & $15 \%$ \\
\hline \multirow{2}{*}{$\begin{array}{l}\text { Perfil } \\
\text { dos } \\
\text { profissionais }\end{array}$} & $\begin{array}{l}\text { Professores com } \\
\text { PhD ou doutorado }\end{array}$ & $95 \%$ & $100 \%$ & $100 \%$ & $100 \%$ & $90 \%$ & $100 \%$ \\
\hline & $\begin{array}{l}\text { Professores com } \\
\text { atividades em } \\
\text { empresas }\end{array}$ & $100 \%$ & $100 \%$ & $100 \%$ & $50 \%$ & $70 \%$ & $100 \%$ \\
\hline \multirow[b]{5}{*}{$\begin{array}{l}\text { Perfil } \\
\text { dos alunos }\end{array}$} & Média de idade & 36 anos & 28 a 32 anos & 40 anos & 35 anos & 35 a 45 anos & 35 a 40 anos \\
\hline & Mulheres & $17 \%$ & $14-17 \%$ & $15-20 \%$ & $30 \%$ & $30 \%$ & $10-12 \%$ \\
\hline & Alta-gerência & $20 \%$ & $20 \%$ & $40 \%$ & $30 \%$ & $10 \%$ & $45 \%$ \\
\hline & Média gerência & $40 \%$ & $40 \%$ & $40 \%$ & $40 \%$ & $70 \%$ & $30 \%$ \\
\hline & Outros & $\begin{array}{c}40 \% \\
\text { (não-gerentes, } \\
\text { consultores, } \\
\text { auditores, } \\
\text { empreendedo- } \\
\text { res) }\end{array}$ & $\begin{array}{c}40 \% \\
\text { (não-gerentes, } \\
\text { profissionais } \\
\text { autônomos) }\end{array}$ & $\begin{array}{c}20 \% \\
\text { (não-gerentes, } \\
\text { profissionais } \\
\text { autônomos, } \\
\text { recém-formados, } \\
\text { professores, } \\
\text { empreendedores) }\end{array}$ & $\begin{array}{c}30 \% \\
\text { (não-gerentes, } \\
\text { empreende- } \\
\text { dores) }\end{array}$ & $\begin{array}{c}20 \% \\
\text { (não-gerentes, } \\
\text { profissionais } \\
\text { autônomos, } \\
\text { recém- } \\
\text { aposentados) }\end{array}$ & $\begin{array}{c}25 \% \\
\text { (não-gerentes, } \\
\text { profissionais } \\
\text { autônomos, } \\
\text { consultores) }\end{array}$ \\
\hline
\end{tabular}

Quanto ao perfil dos professores, é notável o fato de, apesar de praticamente todos serem PhDs, a grande maioria ter atividades fora da academia, seja como executivos em empresas públicas e privadas, seja como consultores.

Além dessas características, três outros aspectos 
merecem destaque: o fato de os MPAs funcionarem como um projeto de renovação para as instituições que os promovem; uma demanda específica dos estudantes por carreiras alternativas; e a questão das novas abordagens pedagógicas. Examinaremos a seguir esses aspectos.

Primeiro, notamos que as instituições consideram os programas como vitrines que podem estreitar seus laços com a comunidade corporativa. Três dos fatores anteriormente mencionados estão relacionados a essa condição: 1) os M PAs são programas de tempo parcial, e, portanto, os estudantes funcionam como um elo de ligação entre as empresas e as escolas; 2) muitas empresas pagam parte das taxas escolares, o que também representa uma conexão entre elas e as escolas; 3) desde a década de 1990 as instituições se tornaram mais dependentes dos investimentos do setor privado, que realizou contribuições significativas em instalações e recursos pedagógicos. Com isso, os programas de M PA também representam projetos de renovação para as instituições que os hospedam.

Segundo, os alunos brasileiros procuram o M PA provavelmente pelos mesmos motivos que seus colegas estrangeiros: reciclagem profissional e ascensão na carreira. Porém, todos os coordenadores de programas entrevistados mencionaram um número representativo de casos de profissionais que vêem no programa uma possibilidade de construir uma nova carreira ou uma carreira paralela, como professores ou empreendedores. Pode-se deduzir que tal condição reflete as mudanças no mercado de trabal ho, que ocorreram devido aos processos de reestruturação e redução de quadros, e ao fraco desempenho da economia brasileira nos anos 1990. Um dos entrevistados, porém, expressou uma razão diferente: muitos estudantes estariam entediados com a vida corporativa e estariam buscando novidades capazes de Ihes abrir a mente para diferentes perspectivas. $\mathrm{N}$ a visão de al guns entrevistados, esses programas se singularizam justamente por responderem às demandas por cursos voltados para 0 empreendedorismo e por proporcionarem a aprendizagem de métodos didáticos.

Terceiro, val e também mencionar a busca de uma nova abordagem pedagógica. Tanto na EA-UFBA quanto na EA-UFRGS, há uma diretriz clara para reduzir as aulas expositivas ao mínimo e implementar novos métodos de aprendizagem. Entre outras iniciativas, os coordenadores dos programas mencionaram: 1 ) alta flexibilidade no desenho dos cursos, buscando adaptação ao perfil de cada turma; 2) um laboratório de gestão e criatividade que usa técnicas de teatro; 3 ) estímulo à troca de experiências entre 0 setor público, o setor privado e o terceiro setor; 4) promoção de uma perspectiva multifuncional e transdisciplinar que busca transcender as fronteiras das áreas tradicionais de conhecimento.

\section{0 processo de diferenciação dos programas}

De um modo geral, pode-se afirmar que os MPAs examinados se diferenciaram entre si, desenvolvendo uma identidade coerente com a história e cultura das instituições que os abrigam.

A FGV-EAESP tem uma forte tradição de escola de negócios, está localizada no maior centro econômicofinanceiro do país, sempre teve forte relação com instituições internacionais e foi pioneira na implantação do novo modelo. O MPA da FGV-EAESP é caracterizado por grandes expectativas dos alunos em relação à ascensão na carreira e por um espírito de competição interpares que faz referência à cultura dos M BAs norteamericanos. Adicionalmente, o público é maciçamente formado por profissionais vindos de grandes empresas. Tais fatores parecem ser determinantes na estrutura e condução do programa, certamente o que mais se aproxima do modelo original norte-americano de MBA.

$\mathrm{Na}$ FGV-EBAPE, a implantação do curso fez parte de um movimento de mudança da instituição, que atuava somente área de administração pública, em direção a um foco mais empresarial. Na EA-UFBA e na EA-UFRGS, a implantação dos cursos está relacionada com o contexto de crise financeira e orçamentária das universidades federais. De criação mais recente, os cursos do IBMEC-RJ e da PUC-RJ seguem a lógica de diferenciação encontrada nos demais cursos, porém parecem ainda estar em processo de consolidação de suas identidades.

A lógica que permeia as universidades públicas brasileiras, a história das instituições e a visão pedagógica dos ideal izadores influenciaram fortemente o caráter dos cursos, gerando inovações e experimentações. Embora tenham se aproximado da comunidade empresarial, os programas sofreram também forte influência de uma visão mais crítica da gestão e do papel das empresas na sociedade (similar em alguns casos à expressa pelos pesquisadores de CMS).

\section{DISCUSSÃO}

Esta parte do trabal ho está dividida em duas sub-seções: na primeira tratamos da polêmica acerca da qua- 
lificação dos M PAs como M BAs; e na segunda identificamos e descrevemos os fatores que levaram os MPAs a configurações distintas entre si.

\section{Ser ou não ser MBA: eis a questão}

Existe uma polêmica, de difícil solução, sobre a qualificação dos M PAs brasileiros como MBAs. Do ponto de vista do mercado, podemos dizer que a associação é legítima: os MPAs (locais) e os MBAs (estrangeiros) destinam-se ao mesmo nicho (perfil de público) e apresentam propostas aparentemente similares. Significativamente, os rankings das revistas AmericaEconomia e VocêS.A. utilizam tal classificação. Também ao olhar estrangeiro, a equação MPA = MBA faz sentido, pois 0 $M P A$ é o que mais próximo temos do modelo original norte-americano.

Porém, essa visão talvez seja simplista e encubra diferenças substantivas, muitas delas já observadas na seção anterior. Se anal isarmos os processos de formação histórica de tais cursos, sua configuração e suas propostas de conteúdo e didática, concluiremos que os M PAs diferem significativamente dos MBAs estrangeiros, aproximando-se em al guns casos dos cursos de mestrado stricto sensu locais, noutros dos cursos de especialização lato sensu também locais, dos quais certamente herdaram muitos atributos.

Verificamos em nossa pesquisa, por parte dos entrevistados, uma ten dência à negação do rótulo MBA para designar os M PAs. Entretanto, essa negação não acontece sem ambigüidades. No Brasil, o uso da sigla M BA ocorre de forma livre de controle: a sigla é utilizada tanto para designar os MBAs executivos - programas de pós-graduação lato sensu - como para designar cursos variados de especialização, inclusive cursos fechados de longa duração para empresas.

Apesar disso, os MPAs continuam sendo informalmente chamados de MBAs. Durante as entrevistas, mesmo que anteriormente refutada, a sigla às vezes surgia espontaneamente para designar o curso. Apesar de haver uma insistente negação da sigla, aceita-se amplamente que os cursos sejam designados como MBAs no ranking publicado anualmente pela revista de negócios Você S.A., que constitui a principal referência local sobre os programas.

0 uso da sigla MBA está relacionado a uma necessidade mercadológica; já a sua negação remete ao desejo de diferenciação. Pode-se estabelecer a hipótese de que, na impossibilidade de afirmar "eles não são MBAs", para se referirem aos demais model os concorrentes, os responsáveis pelos MPAs tenham passado a afirmar: "nós não somos MBAs".

Conforme averiguamos, os M PAs brasileiros constitu em model o híbrido: não seguem completamente a tradição dos M BAs norte-americanos, porém tampouco constituem transposições diretas dos mestrados acadêmicos e cursos de especialização que os precederam, e pel os quais também foram influenciados. Como produto híbrido, o modelo - ou modelos, se considerarmos que cada instituição trilhou caminho próprio - apresenta uma série de tensões, ambigüidades e contradições, algumas de difícil solução.

Entre tais tensões, pudemos observar: 1) a presença, entre professores e coordenadores, do discurso da crítica versus as expectativas instrumentais dos alunos; 2 ) as exigências de dedicação dos programas versus os limites dados pel o vínculo empregatício dos alunos; e 3) a formação orientada para a prática empresarial versus a demanda por formação docente ou empreendedora de al guns alunos.

Por outro lado, os MPAs brasileiros possuem algumas características similares às do Programa de Desenvolvimento Internacional de Executivos proposto por Mintzberg e Gosling (2002): 1) o propósito de praticar uma abordagem interdisciplinar, presente em alguns programas pesquisados; 2) o perfil de experiência profissional dos alunos; 3) o fato de que os al unos continuam suas atividades profissionais durante o curso; 4) a vivência internacional possibilitada pelos intercâmbios com instituições internacionais; e 5) o tamanho reduzido das turmas, que permite maior interação entre os estudantes e destes com os professores.

Adicionalmente, a consciência em relação ao contexto local, revelada pelos entrevistados, sugere uma tendência de resistência à importação de modelos estrangeiros, que é um dos principais fatores apontados por Chanlat (1996) e comentados por Sturdy e Gabriel (2000) para gerar mudanças na educação, na área de gestão.

\section{Fatores que contribuíram para 0 desenvolvimento e condição atual dos MPAs}

Neste ponto do artigo, acreditamos ser oportuno tratar dos "fatores de entrada" e dos "fatores condicionantes", que contribuíram para o desenvolvimento dos MPAs. D efinimos como "fatores de entrada" os componentes primordiais dos programas e, como "fatores condicionantes", os componentes que estimulam ou reprimem certos traços dos programas.

0 primeiro fator de entrada é o processo por meio do qual os M PAs foram criados e a influência dos modelos estrangeiros. Antes de desenvolver seus progra- 
mas, as escolas brasileiras de Administração estudaram os MBAs norte-americanos e europeus. Os meIhores programas foram usados como referências. Acreditamos que esse fator de entrada influenciou todos os aspectos dos programas: o desenho global, a estrutura, o conteúdo e a pedagogia.

0 segundo fator de entrada é a existência de recursos e competências organizacionais e individuais. A criação dos programas de M PA sucedeu, em geral, à criação de programas de graduação e mestrado. Podese então estabelecer a hipótese de que os recursos e competências disponíveis tenham condicionado o desenho dos MPAs em termos de carga horária, planos de ensino, conteúdo e pedagogia. Há, conseqüentemente, um componente de reprodutibilidade ou inércia na criação dos programas de M PAs. Este segundo fator é responsável pelos seguintes traços dos programas: incentivo à reflexão, reconhecimento da importância do pensamento crítico, foco na teoria e, por ou tro lado, uma certa complacência em rel ação a conteúdos e a métodos de ensino desatualizados.

0 primeiro fator condicionante é a influência do contexto local, tanto no nível nacional como no regional. Os programas que analisamos refletem os ambientes sócio-econômicos circundantes, que diferem muito entre as regiões brasileiras. Esse fator provavelmente é responsável por diferentes orientações, em termos de conteúdo, nos programas: orientação para pequenas e médias empresas (EA-UFRGS), orientação para organizações sem fins lucrativos (EA-UFBA) e orientação para empresas de grande porte no setor industrial e de serviços (IBMEC-RJ e FGV-EAESP). Como resultado, os programas adqui riram diferentes contornos em termos de conteúdo e estrutura.

0 segundo fator condicionante é a adoção de referências importadas: livros-texto, manuais e modelos teóricos. Notamos um uso maciço de referências estrangeiras nos programas analisados, inclusive, em alguns casos, de livros de gurus de gestão e livros de auto-ajuda empresarial, que viemos a classificar como literatura de pop-management. É preciso observar que a tradição de usar livros estrangeiros, assim como a limitada disponibilidade de material nacional de qualidade para os cursos de pós-graduação, age como um vetor a favor da continuidade da condição da Administração como um campo importado. Por ou tro lado, constatamos diferenças entre os programas: enquanto alguns deles foram mais influenciados pela perspectiva sociológica, e adotam livros de origem européia e textos produzidos no campo dos CMS, outros optam por manuais norte-americanos de gestão e textos utilizados nos M BAs estrangeiros. Este fator condicionante certamente influencia o conteúdo dos programas e ajuda a moldar a sua abordagem geral - perspectivas mais críticas ver sus perspectivas mais instrumentais.

0 terceiro fator condicionante é a não disponibilidade dos estudantes brasileiros para a dedicação exclusiva aos cursos. Isso obviamente reduz o foco nos estudos, mas por outro lado favorece a interação entre a teoria e a prática de gestão, alterando decisivamente a dinâmica dos cursos e abrindo novas rotas para reflexão. Adicionalmente, podemos inferir que este fator aumenta a pressão pela instrumentalidade, uma vez que muitos estudantes procuram instintivamente soluções para os seus problemas imediatos de trabalho. Este terceiro fator condicionante causa impacto em termos de carga horária e pedagogia.

0 quarto fator condicionante é a presença de competição interna e externa aos programas de MPA. A competição interna é representada por outros cursos oferecidos pela mesma instituição e que se dirigem ao mesmo público-alvo. Com algumas exceções, as escolas de negócios que participaram de nossa pesquisa oferecem, além dos M PAs, outros cursos voltados para executivos. A competição externa é representada por outras escolas de negócios, tanto locais como estrangeiras, que disputam o mesmo público. Esse contexto leva os programas de MPA a desenvolverem estratégias competitivas, na tentativa de criar marcas fortes e oferecer soluções diferenciadas e atrativas para os potenciais candidatos. De acordo com um dos entrevistados, há um componente de sedução no relacionamento entre o curso e seu público. Esse componente pode ser também um vetor condicionante para escoIhas de conteúdo e al ternativas pedagógicas.

0 quinto fator condicionante é a demanda direta aos estudantes por interferência no desenho dos programas. Em processos formais e informais de avaliação, bem como em sua interação direta com professores e coordenadores, os estudantes usualmente transmitem suas necessidades e expectativas. Mesmo que tal apreciação não seja muito elaborada, exerce alguma influência nos programas. Nesse sentido, a pressão por novidades e soluções práticas pode dirigir 0 curso para conteúdos atualizados. Porém, pode igualmente levá-lo para uma trilha excessivamente instrumental e de baixa consistência.

0 sexto fator condicionante relaciona-se à demanda das empresas. Tal influência não parece ser exercida diretamente, porém é clara a intenção de formar pro- 
Quadro 2 - Fatores que contribuíram para o desenvolvimento e condição atual dos MPAs.

\begin{tabular}{|c|c|c|c|}
\hline FATORES & $\begin{array}{l}\text { IMPACTO NA ESTRUTURA E } \\
\text { ESTRATÉGIA DO PROGRAMA }\end{array}$ & $\begin{array}{l}\text { IMPACTO NO CONTEÚDO } \\
\text { DO PROGRAMA }\end{array}$ & $\begin{array}{c}\text { IMPACTO NA PEDAGOGIA } \\
\text { DO PROGRAMA }\end{array}$ \\
\hline $\begin{array}{l}\text { Fator de entrada } 1 \\
\text { Benchmarking com os progra- } \\
\text { mas estrangeiros de MBA }\end{array}$ & $\begin{array}{l}\text { - Desenho global: público-alvo, } \\
\text { objetivos pedagógicos, estrutu- } \\
\text { ra geral dos programas }\end{array}$ & $\begin{array}{l}\text { - Abordagem generalista } \\
\text { - Uso da divisão tradicional do } \\
\text { conhecimento baseada nas } \\
\text { áreas de expertise }\end{array}$ & - Uso do método do caso \\
\hline $\begin{array}{l}\text { Fator de entrada } 2 \\
\text { Uso de recursos e competên- } \\
\text { cias existentes }\end{array}$ & $\begin{array}{l}\text { - Reprodutibilidade ou inércia } \\
\text { em relação aos programas já } \\
\text { oferecidos pela mesma insti- } \\
\text { tuição }\end{array}$ & $\begin{array}{l}\text { - Foco na teoria e teorização } \\
\text { - Reconhecimento da impor- } \\
\text { tância do pensamento crítico } \\
\text { - Complacência com conteúdos } \\
\text { desatualizados }\end{array}$ & $\begin{array}{l}\text { - Foco na teoria e teorização } \\
\text { - Atenção à reflexão } \\
\text { - Reconhecimento da impor- } \\
\text { tância do pensamento crítico } \\
\text { - Complacência com conteúdos } \\
\text { desatualizados }\end{array}$ \\
\hline $\begin{array}{l}\text { Fator condicionante } 1 \\
\text { Contexto local, nacional } \\
\text { e regional }\end{array}$ & $\begin{array}{l}\text { - Diferenciação entre os pro- } \\
\text { gramas }\end{array}$ & $\begin{array}{l}\text { - Conteúdos e estrutura orien- } \\
\text { tados para a realidade das fir- } \\
\text { mas nas diferentes regiões }\end{array}$ & \\
\hline $\begin{array}{l}\text { Fator condicionante } 2 \\
\text { Adoção de referências } \\
\text { importadas }\end{array}$ & $\begin{array}{l}\text { - Contínuo status da Adminis- } \\
\text { tração de empresas como um } \\
\text { "campo importado" }\end{array}$ & $\begin{array}{l}\text { - Adoção de livros de pop- } \\
\text { management } \\
\text { - Adoção de referências euro- } \\
\text { péias e textos de CMS }\end{array}$ & \\
\hline $\begin{array}{l}\text { Fator condicionante } 3 \\
\text { Estudantes sem disponibili- } \\
\text { dade para dedicação integral }\end{array}$ & & - Estímulo ao "instrumentalismo" & $\begin{array}{l}\text { - Estímulo à interação entre } \\
\text { a teoria e a prática } \\
\text { - Pressões em relação à carga } \\
\text { horária } \\
\text { - Foco limitado nas atividades } \\
\text { acadêmicas }\end{array}$ \\
\hline $\begin{array}{l}\text { Fator condicionante } 4 \\
\text { Presença de competição } \\
\text { interna e externa }\end{array}$ & $\begin{array}{l}\text { - Tentativa de desenvolver uma } \\
\text { marca e estratégias de seg- } \\
\text { mentação } \\
\text { - Tentativa de alinhar-se com as } \\
\text { expectativas do mercado }\end{array}$ & $\begin{array}{l}\text { - Estímulo à sedução dos es- } \\
\text { tudantes por meio de conteú- } \\
\text { dos apelativos }\end{array}$ & $\begin{array}{l}\text { - Estímulo à sedução dos estu- } \\
\text { dantes por meio de pedagogia } \\
\text { apelativa (professores-celebri- } \\
\text { dades) }\end{array}$ \\
\hline $\begin{array}{l}\text { Fator condicionante } \mathbf{5} \\
\text { Demanda dos estudantes }\end{array}$ & & $\begin{array}{l}\text { - Pressão por novidades e so- } \\
\text { luções práticas levando à } \\
\text { uma orientação para modis- } \\
\text { mos gerenciais }\end{array}$ & $\begin{array}{l}\text { - Estímulo para que os profes- } \\
\text { sores ajam como entertainers }\end{array}$ \\
\hline $\begin{array}{l}\text { Fator condicionante } 6 \\
\text { Demandas indiretas das } \\
\text { empresas }\end{array}$ & & $\begin{array}{l}\text { - Pressão por novidades e so- } \\
\text { luções práticas: orientação } \\
\text { para modismos gerenciais } \\
\text { - Estímulo ao } \\
\text { "instrumentalismo" }\end{array}$ & \\
\hline
\end{tabular}


fissionais que atendam as necessidades do mercado e das organizações. Assim, a interpretação que coordenadores e professores fazem dessas necessidades pode influenciar tanto o conteúdo quanto o projeto pedagógico. Este fator também ten de a aumentar a pressão pela instrumentalidade.

O Quadro 2 apresenta os oito fatores com respectivos impactos organizados em três categorias: 1) impacto na estratégia geral e estrutura do programa; 2 ) impacto no conteúdo; e 3) impacto na pedagogia. É importante observar que al guns fatores condicionantes têm impacto em mais de uma categoria. Além disso, notamos que certos fatores somaram forças contraditórias no desenvolvimento dos programas, o que sinaliza mais uma vez a existência de tensões.

\section{CONCLUSÃO}

\section{Comentários finais}

Este artigo abordou o fenômeno do ensino da Administração no Brasil, no nível de pós-graduação e focado no público executivo. Ao eleger os MPAs como objeto de anál ise, excluímos outros programas expressivos. Ainda assim, consideramos a estratégia de pesquisa adequada, uma vez que os MPAs representam parte significativa do fenômeno.

Nossa investigação nos leva a concluir que os MPAs constituem um exemplo da estratégia do possível: 0 desenvolvimento e a realização de programas pequenos, que buscam responder às demandas do mercado a partir da articulação da base de recursos existentes e da experiência acumulada. Entre inovações e contradições, os MPAs constituem um retrato significativo das características do ensino da Administração no Brasil, com suas tensões, seu hibridismo e sua diversidade. Podem também vir a sinalizar alternativas de renovação. Para que isso ocorra, acreditamos que quatro desafios básicos precisam ser encaminhados.

0 primeiro desafio trata do conteúdo. Ainda que constituam cursos de elite, os MPAs brasileiros utilizam conteúdos defasados e excesso de material importado - com problemas de adequação ao contexto local. 0 uso de livros de pop-management é especialmente preocupante. Evidências anedóticas nos levam a especular que isso se deve à reciclagem insuficiente dos professores, à prática ainda restrita de ciclos de melhoria contínua dos cursos e a uma tendência de buscar economias de escala e escopo, utilizando 0 mesmo material para vários cursos. Adicionalmente, é preciso enfrentar de forma mais direta a questão da interdisciplinaridade e a questão da ligação com a atividade de pesquisa.

0 segundo desafio refere-se à pedagogia. M esmo que tenhamos registrado iniciativas inovadoras de promoção do aprendizado, o formato dominante ainda são as aulas expositivas. É consenso hoje entre os pedagogos que disciplinas diferentes exigem abordagens didáticas diferentes. Cumpre aos responsáveis pel os programas consolidar os experimentos em andamento e disseminá-los.

0 terceiro desafio refere-se à orientação geral do curso. Os MPAs são programas recentes, desenvolvidos a partir de proj etos originados por estudos e reflexões, e mediados pelo que denominamos "estratégia do possível". Tal condição deve ser vista como uma utilização inteligente das competências existentes; pode também ser vista como uma acomodação à inércia e aos recursos já em estoque nas instituições. N ossa investigação nos leva a crer que os cursos existentes são "projetos fracos", que não enfrentaram devidamente certas tensões e ambigüidades. Daí a condição de hibridismo e de identidade insuficientemente definida. Cumpre desenvolver uma renovação dos programas que considere de forma mais objetiva a demanda da sociedade, das empresas e dos estudantes.

0 quarto desafio refere-se à questão da escala. A maioria dos cursos analisados são pequenos, em termos de número de alunos. N em os mais antigos parecem ter conseguido expandir suas atividades, mesmo operando em um ambiente de forte demanda. Acreditamos, com base no material de pesquisa, que é preciso analisar mais adequadamente a questão da expansão, local e internacional. A manutenção da escala atual pode representar riscos, pela competição agressiva de outros cursos e instituições, e pela consolidação de uma postura de isolamento.

\section{Futuras pesquisas}

Consideramos que este é um trabal ho introdutório, a ser complementado por estudos que podem aumentar sua abrangência e profundidade. U ma primeira alternativa seria investigar os demais cursos de pós-graduação executiva: MBAs Executivos e outros cursos de extensão que adotam o título de MBA, inclusive programas fechados para empresas. Uma segunda alternativa seria aprofundar o estudo do impacto dos cursos sobre os al unos. Tal investigação poderia envolver aspectos quantitativos - crescimento de salários e ascensão na carreira - e qual itativos - aumento das com- 
petências, melhoria da capacidade analítica e crítica e mudança de valores. U ma terceira alternativa seria aprofundar, por meio de um estudo de caso, a avaliação das tensões e contradições presentes nos diversos programas.

Acreditamos que, como parte da indústria do management, os M BAs representam não apenas um objeto interessante de pesquisa, mas simbolizam o espírito da época. Trata-se de um fenômeno rel evante, marcado por paradoxos e ambigüidades, e com amplos impactos sobre a prática gerencial e a vida social.

\section{Artigo recebido em 14.07.2003. Aprovado em 09.11.2003.}

\section{Notas}

Este artigo passou pelo processo usual de double blind review. Porém, em função da posição dos autores na estrutura da RAE, o processo foi coordenado por um editor externo convidado. Tal procedimento foi adotado para garantir a independência da avaliação e a legitimidade do processo.

Agradecemos ao trabalho voluntário de três avaliadores anônimos, que apresentaram valiosas sugestões e permitiram aos autores testar a consistência de alguns caminhos e escolhas.

Agradecemos aos entrevistados, que partilharam de forma aberta suas experiências e opiniões.

Este trabalho foi realizado com apoio do N PP, da FGV-EAESP.

\section{Referências Bibliográficas}

ADLER, P. Corporate scandals: It's time for reflection in business schools. The Academy of Management Executive, v. 16, n. 3, p. 148-149, 2002.

ALVESSON, M.; DEETZ, S. Critical theory and postmodernism approaches to organizational studies. In: CLEGG, S.; HARDY, C.; NORD, W. R. (eds.) Handbook of Organization Studies. London: Sage, 1996.

ALVESSON, M.; WILLMOTT, H. (eds.) Critical Management Studies. London: Sage, 1992.

ALVESSON, M.; WILLMOTT, H. (eds.) Making sense of management: A critical analysis. London: Sage, 1993.

ANTONACOPOULOU, E. P. Teaching "critical thinking" to MBAs. Proceedings of the 1 st International Critical Management Studies Conference. Manchester: UMIST, 1999.
BOJE, D. M. Management education as a panoptic Cage. In: FRENCH, R. GREY, C. (eds.) Rethinking M anagement Education. London, Sage, p. 172195, 1996.

CASTRO, C. M. 0 ensino da administração e seus dilemas: Notas para debates. Revista de Administração de Empresas, v. 21, n. 3, p. 58-61, 1981.

CHANLAT, J. F. From cultural imperialism to independence. In: CLEGG, S. R.; PALMER, G. (eds.) The Politics of Management Knowledge. London: Sage, p. 121-140, 1996.

DEHLER, G.; WELSH, M. A.; LEWIS, M. W. Critical pedagogy in the "new paradigm": Raising complicated understanding in management learning.

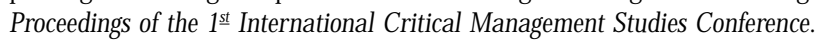
Manchester: UMIST, 1999.

ENRENSAL, K. N. Critical management studies and American business school culture: Or, how NOT to get tenure in one easy publication. Proceedings of the 1 st International Critical Management Studies Conference: Manchester, UMIST, 1999.

EWING, D. Inside the Harvard Business School. New York: Times Book, 1990.

FOX, S.; GREY, C. Introduction: Connecting learning and critique. Management Learning, v. 31, n. 1, p. 7-10, 2000.

GIOIA, D. A. Business education's role in the crises of corporate confidence. The Academy of Management Executive, v. 16, n. 3, p. 142-144, 2002.

GIOIA, D. A.; CORLEY, K. G. Being good versus looking good: Business school rankings and the circean transformation from substance to image. Academy of Management Learning and Education, v. 1, n. 1, p. 107-120, 2002.

GOLD, J.; HOLMAN, D.; THORPE, R. The manager as a critical reflective practitioner: Uncovering arguments at work. Proceedings of the $1^{\text {st }}$ International Critical Management Studies Conference. Manchester: UMIST, 1999.

GOMES, M. T. MBA ajuda? Exame, 23 de outubro, p. 47-54, 1996.

GREY, C.; FRENCH, R. Rethinking management education: An introduction. In: FRENCH, R.; GREY, C. (eds.) Rethinking management education. London: Sage, p. 1-17, 1996.

GREY, C.; KNIGHTS, D.; WILLMOTT, H. Is a critical pedagogy of management possible? In: FRENCH, R.; GREY, C. (eds.) Rethinking management education. London: Sage, p. 94-110, 1996.

JACOMINO, D. A meta é um MBA. VocêS.A., n. 12, p. 100-103, 1999.

JACOMINO, D. Quem são os brasileiros que fazem MBA lá fora. VocêS.A., n. 21, p. $17,2000$. 
JACOMINO, D. Os melhores MBAs do planeta. Você S.A., n. 32, p. 24, 2001.

LINDER, J.; SMITH, H. J. The complex case of management education. Harvard Business Review, v. 70, n. 5, 1992.

MARTINS, C. B. Surgimento e expansão dos cursos de Administração no Brasil (1952-1983). Ciência e Cultura, v. 41, n.. 7, p. 663-676, 1989.

MINTZBERG, H.; GOSLING, J. Educating managers beyond borders. Academy of $M$ anagement Learning and Education, v. 1, n. 1, p. 64-76, 2002.

MINTZBERG, H.; LAMPEL, J. MBAs as CEO s. Fortune, February 19, 2001.

NICO LINI, A. Qual será o futuro das fábricas de administradores? Revista de Administração de Empresas, v. 43, n. 2, p. 44-53, 2003.

PARKER, M.; JARY, D. The MCUniversity: Organizations, management, and academic subjectivity. Organization, v. 2, n. 2, p. 319-338, 1995.

REYN OLDS, M. Towards a critical management pedagogy. In: BURGOYNE, J.; REYN OLDS, M. (eds.). M anagement learning: Integrating perspectives in theory and practice. London: Sage, p. 312-338, 1997.

RITZER, G. The M cD onaldization of Society. N ewbury Park, CA: PingeFonge Press, 1993.

ROBERT, J. Management education and the limits of technical rationality: The conditions and consequences of management. In: FRENCH, R.; GREY, C. (eds.) Rethinking management education. London: Sage, p. 54-75, 1996.
RUAS, R. Mestrado modalidade profissional: Em busca da identidade. Revista de Administração de Empresas, v. 43, n. 2, p. 55-63, 2003.

SCHNEIDER, M. Learning to put ethics last. BusinessWeek, March 11, 2002.

SGANZERLA, V. Vale a pena fazer um MBA lá fora? Exame, 6 de dezembro, p. 108-110, 1995.

STURDY, A.; GABRIEL, Y. Missionaries, mercenaries or car salesmen? MBA teaching in Malaysia. Journal of Management Studies, v. 37, n. 7, p. 9791002, 2000.

THE ECONOMIST. December 14 - 20, p. 79-83, 2000a.

THE ECONOMIST. December 21"- January 3, p 124-137, 2000b.

VOCÊ S.A. Os melhores MBAs do Brasil. Edição Especial, 2000.

VOCÊ S.A. Os melhores MBAs do Brasil. Edição Especial, 2001.

WARDE, I. Fascinantes business schools. Le M onde Diplomatique, v. 1, n. 3, maio, 2000. (http://www. diplo. com. br/).

WARNER, A. Where business school fail to meet business needs. Personnel Management, v. 22, n. 7, p. 52-46, 1990.

WILLMOTT, H. Management education: Provocations to a debate. Management Learning, v. 25, n. 1, p. 105-136, 1994.

\section{Thomaz Wood Jr.}

Professor da FGV-EAESP. Doutor em Administração de Empresas pela FGV-EAESP. Interesses de pesquisa em teoria das organizações, a "espetacularização" da vida corporativa e novas configurações organizacionais.

E-mail: twood@grgsp.br

Endereço: Avenida Nove de Julho, 2029 - 10ํo andar - São Paulo - SP, 01313-902.

\section{Ana Paula Paes de Paula}

Pós-doutoranda em Administração na FGV-EAESP e Pesquisadora da FAPESP. Interesses de pesquisa em teoria das organizações, administração pública e ensino e pesquisa em administração.

Email: appaula@uol.com.br

Endereço: Avenida Nove de Julho, 2029 - 9o andar - São Paulo - SP, 01313-902. 